\title{
Post-experimental phases of IT across the curriculum projects: the Spanish view
}

Carlos San José

Programa de NTIC, Ministerio de Educación y Ciencia Madrid, Spain

\begin{abstract}
This paper describes how the new information and communication technologies - mainly computers - have been introduced in secondary education in Spain. Eight different plans for the introduction of IT in education are being carried out at the moment in Spain, but this paper deals only with the ATENEA Project, managed by the Central Government's Ministry of Education. The main topics covered here include policy-making concerning software and hardware, teacher training and Telematics. Some remarks, relevant from the point of view of a well implemented, post experimental Plan, have also been included regarding the main issues involved in the educational use of IT and its integration in the curriculum.
\end{abstract}

Keywords: management, national policies, teacher training, communication 


\section{INTRODUCTION}

This paper describes how the new information and communication technologies - mainly computers - have been introduced in the structure of Spanish secondary education.

The structure of Government and Administration in Spain is becoming territorially decentralized through a process that affects every sphere of social life, including education. Jurisdiction on educational matters has already been transferred to the local authorities of seven of the seventeen Autonomous Regions (Comunidades Autsnomas), but in the other ten roughly speaking, half the territory of Spain - education is still managed but the Central Government's Ministry of Education. For that area, the Ministry created a department called Program for New Information and Communication Technologies (PNTIC), which is in charge of the introduction of IT in the schools (i.e. education below university level), and has developed a plan called ATENEA Project.

Similar projects have been implemented in the seven Regions with full jurisdiction over education, but the ATENEA Project is the most important of all the national plans in terms of size. In spite of their differences, the eight plans share some common features. In order to achieve cooperation and convergence, the heads of the projects hold frequent meetings, chaired by the Director of the PNTIC and the ATENEA Project.

\section{THE ATENEA PROJECT}

Educational projects which are innovative both in their contents and their context cannot be implemented by national ministries or departments of education without a prior assessment of their global impact on the whole educational system. It is essential not to neglect the impact of IT projects on regulated activities (curriculum) and school management and organization (classroom space, timetables), or the various factors involved in teacher training, to mention but a few of the main key issues.

In operational terms, the feasibility of such projects depends on policy-making at three levels: hardware, software and teacher training. Projects can be judged according to way these three critical factors are dealt with.

From this point of view, comparisons between the different member states of the European Union [1], and even between different nations in other areas of the world [2], show that approaches are very similar in most 
countries, the only important differences arising from issues concerning centralization or decentralization.

\section{Hardware policy}

The first of the above mentioned critical levels of policy-making comprises the most conspicuous aspect of any Project: choice of standards, big investment planning, site enhancement, contracts on hardware maintenance, design of the distribution network, etc. In the Atenea Project, decisions on the provision of equipment are centralized due to purchasing costs, although many public schools may have alternative means to provide themselves with equipment.

In this respect, centralization has many advantages over decentralization, which implies in practical terms that schools or small groups of schools have to buy their own hardware. Strength in big numbers, both at the initial purchase and for the subsequent maintenance scheme, is a key factor.

\section{Software policy}

It is important to have a clear policy in this field, due both to linguistic-cultural implications and issues concerning national industries. When the first projects were launched in Spain, around 1985, there was hardly any software available in the Spanish market which could qualify as "educational". The solution that was then adopted was to resort to general purpose software and explore its educational potential. Some integrated packages were (and still are) used to develop the pedagogical use of word processors and data bases. Spreadsheets were less frequently used, due to their complexity and difficulty of use.

At present a remarkable amount of educational software is available from different sources, always in national versions.

Regarding software, language is a delicate issue in any country where English is not the native tongue. Taking into account the age of potential users, and their non-professional (or pre-professional) condition, the Spanish Ministry of Education decided from the start that all the software used in schools had to comply with the sine qua non requisite of being in Spanish. The Spanish-speaking market is big enough all over the world (300 millions of native speakers) so as to lure both big and small firms into producing Spanish versions of their programs. This requisite has been seriously fulfilled.

Two other initiatives of even greater importance have also been implemented in this area, in order to encourage the creation of a national educational software market, with Spanish characteristics. The Ministries 
of education and Industry signed an agreement to jointly provide funds for $\mathrm{R}+\mathrm{D}$ projects, an initiative which has helped to fix standards (concerning interfaces, prices, distribution networks, etc.) in the Spanish market. On the other hand, public software contests have been organized periodically, offering substantial awards. About one hundred good quality programs have been obtained from this source, their copyrights now belonging to the Ministry of Education.

\section{Teacher Training}

This is probably the most important issue. Hardware affairs are largely a money matter, and software issues, being more complex, can be solved with the effort of a relatively small team. But the decisive factor on which the success of the whole plan depends is teacher training. This fact is widely recognised in most of the international literature [1],[2] and [4].

In Spain, a pre-existing network of Teachers Centres was enhanced and used to provide training in the educational use of IT. Plans for teacher training are developed at two levels. Some teachers are temporarily relieved of their normal duties in order to receive intensive training and a specialized instruction, which enables them to impart seminars and provide advice to other teachers. There is a vast network (113) of Teachers Centres at the moment, there being one of these IT specialists in each and every one of them. The rest of the teachers involved in IT activities at their schools may receive general training outside their normal working hours, as they are not relieved of their duties.

In every school participating in the Atenea Project there is a Supervisor and a teacher in charge of co-ordinating IT activities and providing a link with the Teachers Centre. The Headquarters of the Project provides the training of the supervisors (150 hours) on IT and methodology. The rest of the teachers in the school team receive their basic training at the local Teacher Centres.

Finally, it is to be mentioned that the network of Teachers' Centres seems to be quite capable of catering for the training needs of private or public sector teachers interested in IT. Nevertheless, the negative fact that training cannot be imparted within normal teaching hours, which seriously hinders its expansion to a massive scale, will have to be confronted in the future. The most fruitful policy in this respect would be to include IT in pre-service training. In the meantime, Telematics and distance training will have to play a more decisive role in teacher training, as is showed in the experiments already done. 


\section{Objectives}

The objectives of the ATENEA Project may be summarized as follows.

\section{Focussing on the students}

- To favour cognitive development and innovative learning by means of new environments.

- To stimulate critical understanding and rational uses of new technologies as means of expression.

- To enable students to access, organize and process information by means of new technologies.

Focussing on the teachers

- To provide the technical support and the proper training which will enable them to use computers as pedagogical tools and instruments for innovation and improvement.

- To enable them to select and analyze the resources best suited to their environment and their specific tasks.

- To improve the management and organization of schools.

\section{Focussing on the Curriculum}

- To establish patterns for the integration of NIT in the different curricular areas.

- To enhance the influence of computer science and information technology in the curriculums of all types of general and specialized instruction.

\section{Equal Opportunities}

Equality of opportunities for women has been considered of paramount importance. Special courses for female teachers have been organized with the aim of encouraging projects launched by women, and counterbalance the male monopoly of IT, both as regards teachers and students. However, as the problem has been detected mainly in the teaching profession, measures have been taken mainly to provide female teachers with equal opportunities. On the other hand, although there does not seem to be a noticeable male predominance in the use of IT by students, more careful studies are being carried out in order to establish whether the general technological orientation of males may be mirrored in the field of IT in the future.

Other actions are being carried out for students with special needs and underprivileged social groups. New technologies have proved to be useful tools for the integration of these groups, and the future trend is toward increasing actions in this field (specific training for teachers, production of materials, provision of equipment to schools). 


\section{The evaluation of the ATENEA Project}

The ATENEA Project was evaluated by the OECD [3] in 1990. This process was the final stage of the so-called pilot phase of the Project (1985-1990). The evaluation team analyzed every dimension of the Project and elaborated a set of considerations and warnings that have been the basis for the Project's continuity into the extension phase. The Project is reaching at the moment its last stage - the generalization phase. This is the natural next step and will provide every Spanish secondary and primary public school with access to the facilities, within the framework of the educational system defined by the new legislation recently introduced (1992).

Some of the problems detected by the evaluators were: the lack of pre-existing materials developed for an innovative project, and the slow pace of implementation of the whole Project, mainly due to the amount of time necessary for software development and the slowness and complexity of the purchasing mechanisms after development. The resulting lack of materials has recently become a serious problem.

Problems were also detected in the teacher training process, namely the time span (a whole school term) required for training a specialist, the fact that school teachers received training only on a voluntary basis (outside working hours, and with no supplement to their salaries); and the de-motivating extra work involved in changing habits when using new tools. Problems of school management (organization of space, computer classrooms, security measures, maintenance costs) were also found to be of some importance. Many of these problems are being addressed by the new Education Act, which provides the schools with some independent jurisdiction over curricular design and adaptation as well as timetables and organization schemes.

The OECD Report also touched upon the schemes for the provision of equipment and the horizontal communication between teachers. In the evaluator's opinion, the schools should play a more active role in the provision of their own equipment, which would enable them to become more independent from the centralized policies of the Ministry. This would help to diversify the equipment and would contribute to solve the problems arising from the obsolescence of materials.

\section{TELEMATICS IN EDUCATION: THE PLATEA PLAN}

Following the international trends in the field of educational Telematics [5], and the advice of the OECD Evaluation Report [3], the PNTIC has organised different telematic infrastructures and activities to consolidate 
the links between members of the educational community. The success in this field is one of the indicators of the Project being in a full blossoming phase.

The school Telematics plan is called Platea. The objective of this project is to provide teachers with facilities for communicating, exchanging and disseminating their experiences easily. As such, Platea is also a medium for teacher training. It encourages cooperative work between teachers and pupils in different Spanish or foreign schools, by means of the sharing of experiences and the preparation of joint work. Finally, the Platea plan is trying to help students incorporate the telematic tools in their work.

Two types of networks have been initially created: a central network, and several local networks. The central network, whose node is located in the PNTIC headquarters, is based on the Spanish videotex network, Ibertex. It consists of a Service Centre specifically created for schools, teacher training centres, and academic authorities, although most of its services can be accessed by whoever uses Ibertex. The main advantage of this solution is the low fares scheme (about 3,5 ECU per hour, regardless of distance). The main disadvantage lies in the limitations of the resources (speed, facilities) provided by the network.

The second kind of network is a net of local networks based on the Telephone Switched Network (Red Telefsnica Conmutada, RTC). Each of the 113 Teacher Centres becomes a regional node which can be accessed by means of a local telephone call. These networks can adopt the configuration of a central network, since all users can connect themselves to the PNTIC's node, but the cost of a phone call from outside the local area is too high for a normal school's budget. In the future, depending on negotiations with the Spanish PTT, it could be possible to connect the schools through the RTC network. The next step will be to provide an INTERNET access for every school thus opening them to the broad space of world communications.

\section{THE MENTOR PROJECT: TELEMATICS FOR DISTANCE LEARNING}

The PNTIC is also in charge of the Mentor Project, an experimental plan for open education and distance training for adults by means of telecommunications technology. One of its objectives is to test out these tools and the methodology for their use in education. Training and local 
socio-economic development are its basic aims, with a perspective entirely different from that of other initiatives developed by the PNTIC.

A description of the Mentor Project would be beyond the scope of this document; suffice it to say, however, that it aims to develop open education and training in the less economically successful regions of Spain, and especially in rural areas where access to information and training resources is still a serious problem, in order to improve general culture among young and adult inhabitants of these areas, and to favour communication and access to information.

\section{SOME REMARKS ON IT IN EDUCATION}

Today's citizens must incorporate IT skills to their basic training. The use of certain tools, such as word processors or data bases, has become so unavoidable in intellectual activities of all types, that not using these resources in education would result in a waste of opportunities for enhancing human intellectual potential.

But the situation is far from being static or closed: new software and hardware is continuously being added to the list of indispensable (or at least desirable) educational materials. These tools allow us to perform otherwise impossible tasks, or simplify those which can be carried out by other means, increasing efficiency and reliability.

IT, in contrast with most sectors of trade and industry, shows a steady trend toward decreasing costs, in hardware as much as in software. This factor may allow schools, usually operating on very tight budgets, to access the latest available technologies that may prove to have some educational potential. Continuous investment is therefore required in both hardware and software, as well as in teacher training, which is the most important.

The concept of permanent training is of special importance, as teachers must remain both competent users of IT and competent instructors of the subject matter in which they are specialized. Methodologies, curriculums and school organization change over time, and teachers must keep up to date with these changes, some of which are themselves brought about by IT.

\section{The integration of information technologies in the curriculum}

Existing studies [4] have shown a strong trend towards integration of basic tools in the curriculum on a cross-curricular basis. This can be seen as the "normal" penetration of technology in the specific field of education. 
But IT has also proved its efficiency in certain fields of activity which are now hardly conceivable without them. Such is the case of Special Education, where IT operates as an empowering prostheses, facilitating action which in many cases would otherwise be impossible. In the field of drawing and graphic design, professional activities have undergone such sweeping changes that they are almost exclusively based on the use of IT at the moment - perhaps with the partial exception of the area of artistic creation. The same holds true for education: any curriculum attempting to be complete must include the use of computer aided design and drawing, not because the basic skills required for handling paper, pencil and ink should be discarded, but because there is a whole new horizon of possibilities for experimenting and learning now open even to the non-gifted.

A similar case can be found in the field of the automatisation of technology. There is a kind of technology based on handicraft techniques, and another more advanced type which resorts to IT.

The school newspaper, perhaps the most popular of cross-disciplinary school activities, can also be transformed by the use of IT. This is a very enriching activity which allows for topics of social, literary, or artistic interest to be dealt with, providing at the same time opportunities for the practice of critical and writing skills, and for the development of cooperation between the members of the school community. ITs not only simplify the tasks involved, they also add new dimensions to the pedagogical experience, such us desktop publishing, word processing, Telematics. Other educational areas where the use of ITs is expanding are physics and chemistry laboratories and computer aided musical instruction.

\section{CONCLUSION: TRENDS}

One of the problems we face at the moment is the high costs of hardware in comparison with other types of school equipment, an obstacle which seriously hinders its incorporation to classroom practice. In the Spanish public sector, the only solutions considered for the time being are based on centralized purchase of equipment. In the future, as costs are reduced and computers and peripherals become widespread in different social areas, local institutions will play an important role as equipment providers, and normal school budgets will contemplate the allocation of funds for IT materials less exceptionally than they do now. In the private sector, funds will be obtained from the usual sources, and the pace of development will 
be that established by the law regulating the educational system, and by the example set by the public sector.

With regard to the use of technology in the classroom, three trends are foreseeable. Firstly there will be an increase in curriculum-integrated use, which may rely on higher quality, more specialized and powerful software such as multimedia and LANs. The aim will be to teach skills and concepts by means of new technologies wherever they prove more useful than traditional resources.

Secondly, IT will obviously be used to deal with certain IT-based areas of knowledge, such as CAD, Robotics, infographics, laboratories and microelectronics. The increasingly less important field of programming languages could be included here. Thirdly, computers will be used through word processing, data bases and CD ROM drives for production, access to information, and the management of the teaching and learning process.

\section{REFERENCES}

1. There are 12 Member States Reports on New Information Technologies in Education, elaborated for the Commission of the European Communities-Task Force of Human Resources and published by the Office for Official Publications of the European Communities, Luxembourg (1993): New Information Technologies in Education in: Belgium, Denmark, France, Germany, Greece, Ireland, Italy, Luxembourg, The Netherlands, Portugal, Spain, The United Kingdom. OECD, Luxembourg.

2. Pelgrum, W.J, Jansen, I.A.M. \& Plomp, Tj. (1993) Schools, Teachers, Students and Computers: a Cross-National Perspective. IEA. Enschede.

3. Ministry of Education and Science (1991) Proyecto ATENEA: OECD Evaluation Report. Secretaría de Estado de Educación, Madrid.

4. Ministry of Education and Science (1991) Information Technology in the curricula of the different E.C. Countries. Secretaría de Estado de Educación. Madrid.

5. Veen, W and Vogelzang, F. (1992) Telematics in Dutch Education. Academisch Boeken Centrum, De Lier. 


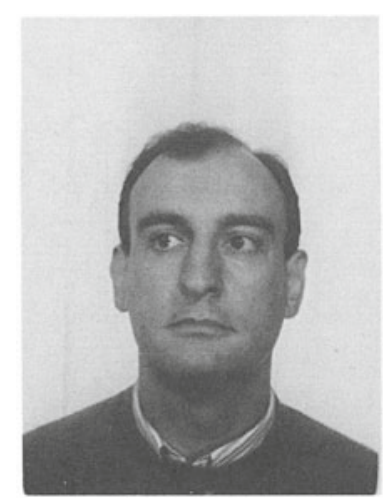

Carlos San José Villacorta is Technical Councillor of the Program for New Information and Communication Technologies (PNTIC), Ministry of Education and Science. After a period as a teacher of mathematics in secondary school, he is now a tenured civil servant in the Systems and Information Technology High Corps, in charge of national and international projects dealing with development, applications and training. Carlos is a member of several directive boards and working groups in European projects dealing with educational software, teacher training and ITC, and computers in education; he also serves on the expertsd panel of the Telematics for Education and Training project of the European Commission. He has written several books and essays on computers in education. 